EGU21-7489, updated on 08 Jun 2021

https://doi.org/10.5194/egusphere-egu21-7489

EGU General Assembly 2021

(c) Author(s) 2021. This work is distributed under

the Creative Commons Attribution 4.0 License.

\title{
Sources of ice block falls at the Martian north polar scarps: detection from multi-temporal HiRISE image sets
}

\author{
Shu Su ${ }^{1}$, Lida Fanara ${ }^{1,2}$, Xin Zhang ${ }^{3}$, Klaus Gwinner ${ }^{2}$, Ernst Hauber ${ }^{2}$, and Jürgen Oberst Kr, $^{1,2}$ \\ ${ }^{1}$ Technical University of Berlin, Institute of Geodesy and Geoinformation Science, Chair of Planetary Geodesy, Berlin, \\ Germany (shu.su@campus.tu-berlin.de) \\ ${ }^{2}$ Institute of Planetary Research, DLR, Berlin, Germany \\ ${ }^{3}$ College of Surveying and Geoinformatics, Tongji University, Shanghai, China
}

The North Polar Layered Deposits (NPLD), which consist of dusty water ice layers, have recorded the climatic variations of Mars. We use High Resolution Imaging Science Experiment (HiRISE) data (ground pixel size of up to $\sim 0.25 \mathrm{~m} / \mathrm{pixel}$ ) to study the morphology and current erosional processes at the NPLD scarps. Fanara et al. $(1,2)$ have performed automated detection of the fallen ice blocks at the foot of scarps. Our aim is to search for their possible source areas.

We apply change detection techniques to multi-temporal images. The images are ortho-rectified using HiRISE Digital Terrain Model (DTM) and then co-registered to ensure subpixel alignment accuracy. Due to the low-sun conditions in Martian polar areas, the surface morphology can be revealed from cast shadows. In addition, HiRISE operates on a nearly sun-synchronous orbit, which means the images are taken at the same local time of day, providing good conditions for automatically detecting changes in shadow patterns of the ice-fragments.

The areas with changed shadows illustrate the spatial distribution of mass wasting activities. Our results show that most of the detached ice-fragments originate from the lower parts of the scarp, which are heavily affected by fracturing. Based on the detected changes, we will further investigate the characteristics of mass wasting and estimate the volume of the detached ice-fragments. The temporal and spatial distribution of detached ice fragments at different NPLD scarps can provide insights into the ice behavior and thus support modelling studies of viscous flow velocities (3), thermoelastic stresses (4) and climate variations of Mars. Ultimately, we intend to explore the evolution of the NPLD scarps by correlating long-term mass wasting characteristics with seasonal and morphological parameters.

\section{References}

[1] Fanara et al.,2020. Planetary and Space Science. 180, p.104733.

[2] Fanara et al.,2020. Icarus. 342, p.113434. 
[3] Sori et al., 2016. Geophysical Research Letters, 43(2), pp.541-549.

[4] Byrne et al., 2017. EPSC, Vol. 11. 